\title{
Sweat Rate and Electrolyte Composition in Young Women of Varying Body Mass Indices during Moderate Exercise
}

\author{
Omorede E. Osayande*, Eloghosa E. Ogbonmwan, Andrew C. Ugwu \\ Department of Physiology, University of Benin, Benin City, Nigeria \\ Email: "omorede@uniben.edu
}

Received 10 January 2016; accepted 4 April 2016; published 7 April 2016

Copyright @ 2016 by authors and Scientific Research Publishing Inc. This work is licensed under the Creative Commons Attribution International License (CC BY). http://creativecommons.org/licenses/by/4.0/

(c) $\underset{\mathrm{EY}}{(1)}$ Open Access

\section{Abstract}

Sweat is a hypotonic fluid excreted by sweat glands to cool the body. There are conflicting reports on whether or not body composition has an effect on thermoregulatory responses especially during exercise. This study was aimed at determining and comparing sweat rate and electrolyte composition in underweight (BMI $\left.<18.5 \mathrm{~kg} / \mathrm{m}^{2}\right)$, normal weight $\left(18.5 \mathrm{~kg} / \mathrm{m}^{2}>\mathrm{BMI}<25 \mathrm{~kg} / \mathrm{m}^{2}\right)$, overweight $\left(25 \mathrm{~kg} / \mathrm{m}^{2}<\right.$ BMI $\left.<30 \mathrm{~kg} / \mathrm{m}^{2}\right)$ and obese women (BMI $>30 \mathrm{~kg} / \mathrm{m}^{2}$ ) during moderate exercise. Forty women (19 - 25 years) were used during this study after assessing their health status. They were stratified for BMI with each group having a total of ten women. It was ensured that all the women used in the study were euhydrated before commencing the research. Before sweat collection, the treadmill was calibrated according to the Bruce Treadmill Protocol. Sweat samples were obtained with a sweat suction apparatus from a $120 \mathrm{~cm}^{2}$ circular area marked on the skin of the face and neck, after a 15 minute fast walk on a treadmill at an inclination of $15^{\circ}$ and at a speed of $4.2 \mathrm{~km} / \mathrm{h}$ at $27^{\circ} \mathrm{C}$ room temperature. The time at which sweating commenced in the subjects was recorded. Sweat rate $(\mathrm{L} / \mathrm{hour})$ was calculated using the formula: sweat rate $(\mathrm{L} / \mathrm{hr})=$ (pre-exercise body weight - Post-exercise body weight)/exercise duration. Each sweat sample was collected and analysed immediately. The results showed that obese women had a significantly ( $\mathrm{P}<$ $0.05)$ higher sweat rate and underweight women had a significantly $(P<0.05)$ lower sweat rate than all the other groups. Furthermore, subjects with a high body surface area showed significantly higher sweat rates compared to subjects with lower body surface area. Sweat electrolyte composition did not change in all BMI groups. In conclusion, obese subjects are more likely to develop fluid imbalances than underweight and normal weight subjects during moderate exercise. Also, underweight women might be at a thermoregulatory disadvantage because of their reduced body fat and body surface area.

\footnotetext{
${ }^{*}$ Corresponding author.
} 


\section{Keywords}

\section{Sweat Rate, Sweat Electrolyte Composition, Thermoregulation, Body Mass Index, Moderate Exercise}

\section{Introduction}

Sweating is a major form of thermoregulation in man. Thermoregulation is a complex system involving chemical, physical and behavioural events that permit the maintenance of body temperature within a constant range under conditions of variable external or internal heat loads [1].

When humans exercise, significant amounts of heat is produced by the body and thermoregulatory mechanisms come into play to return body temperature back to the normal range. Notable amongst these mechanisms is sweat production by the sweat glands [2]. The evaporation of sweat from the skin transfers heat to the environment as water has a high latent heat of evaporation. These same mechanisms also occur in hot environmental temperature conditions.

Body mass index (BMI) is a measurement of weight adjusted for height. It is calculated as weight in kilograms $(\mathrm{Kg})$ divided by the square of height in meters $\left(\mathrm{m}^{2}\right)$. Obesity and underweight may be correlated to distorted physiological responses to exercise [3]-[5]. There however are limited and conflicting reports about the sweat rate and composition of body electrolytes in people of different body mass indices.

The composition of sweat is dependent on the difference between Sodium $\left(\mathrm{Na}^{+}\right)$secreted during the formation of precursor sweat and the rate of reabsorption of ductal $\mathrm{Na}^{+}$[6] [7]. Studies have also shown that the concentration of Sodium $\left(\mathrm{Na}^{+}\right)$in sweat increases proportionally with increases in sweating [8]-[11]. This also applies for chloride $\left(\mathrm{Cl}^{-}\right)$. Ugwu and Oyebola (1992) [12] studied the effects of temperature and exercise on sweat rate and sweat electrolyte loss in Nigerians and observed that exercise and temperature brought about increased in sweating and sodium and potassium ion loss in sweat.

Recently, several studies reported no difference in sweat rate during exercise when obese and lean girls were compared [13] and lean and obese men [14]. In contrast, Eijsvogels et al. (2011) [15] reported that obese subjects showed a larger deviation in markers of fluid and sodium balance than their lean counterparts during prolonged moderate-intensity exercise.

This study therefore aimed at comparing sweat rate and sweat electrolyte composition in underweight, normal weight, overweight and obese women during moderate intensity exercise.

\section{Methodology}

\subsection{Subjects}

40 apparently healthy young women, students of the University of Benin, Ugbowo Campus, aged between 19 25 years were used in this study. Their health status was assessed with the aid of questionnaires and physical examination. It was ensured that all the subjects were in the follicular phase of their menstrual cycle to avoid hormonal influences on sweat rate. Exclusion criteria for the study included history of medical and gynaecological disorders, pregnancy, history of smoking and use of any form of medication in the last six months and the consumption of alcohol and caffeine was also restricted at least 24 hours before the study.

Subjects were put into four groups as determined by their BMI. Groups I, II, III and IX with each consisting of 10 subjects.

Group I-Underweight women (BMI $\left.<18.5 \mathrm{~kg} / \mathrm{m}^{2}\right)$.

Group II-Normal BMI (18.5 - $\left.24.9 \mathrm{~kg} / \mathrm{m}^{2}\right)$.

Group III-Overweight women (BMI- $25-29.9 \mathrm{~kg} / \mathrm{m}^{2}$ ).

Group IX-Obese women $\left(\mathrm{BMI}>30 \mathrm{~kg} / \mathrm{m}^{2}\right)$ [16].

All subjects were fully informed about the objectives and procedures of the study and a signed informed consent form indicating their agreement to participate voluntarily in the study was obtained.

\subsection{Experimental Protocol}

The physiology laboratory of the University of Benin was used for this study. Data collection occurred in the 
morning between 08:00 am and 12:00 noon. It was ensured that all subjects where euhydrated by drinking 600 $\mathrm{mls}$ of water two hours before the commencement of the exercise [17]. For each subject, anthropometric and other baseline parameters were measured. The subjects acclimatized for 30 minutes in the laboratory before exercise began [18]. The BMI of each subject was calculated using the formula;

$$
\text { BMI }=\frac{\text { weight }(\mathrm{kg})}{\text { height }^{2}\left(\mathrm{~m}^{2}\right)}
$$

Subjects were then directed to void their bladders and then weighed again before the exercise was commenced. After exercise, the subjects were weighed again and there was no fluid replacement throughout the exercise.

During the data collection, volunteers wore tops, shorts, socks and sneakers.

\subsection{Subject Characteristics}

Body surface area was calculated according to the formula of Mosteller (1987) [19]. Axillary and room temperature was measured using a digital skin thermometer inserted in the axilla for 90 seconds and room thermometer, respectively. Body weight was measured using a digital weighing scale. Hip circumference was measured at the level of the widest circumference over greater trochanters. Waist circumference was measured midway between the lower rib margin and iliac crest. Waist-to-hip ratio was calculated as waist circumference divided by hip circumference. The Resting pulse rate and blood pressure was measured in the sitting position twice and he average taken using an automated sphygmomanometer after 5 minutes of rest.

\subsection{Sweat Collection}

Before sweat collection, the treadmill was calibrated according to the Bruce Treadmill Protocol [20]. Sweat samples were obtained with a sweat suction apparatus from a $120 \mathrm{~cm}^{2}$ circular area marked on the skin of the face and neck [18], after a moderate exercise, i.e. a 15 minute fast walk on a treadmill at an inclination of $15^{\circ}$ and at a speed of $4.2 \mathrm{~km} / \mathrm{h}$ at $27^{\circ} \mathrm{C}$ room temperature. The time at which sweating commenced in the subjects was recorded. Sweat samples were collected into plain sample bottles and immediately analyzed.

Sweat rate (L/hour) was calculated using the formula below:

Sweat rate $(\mathrm{L} /$ hour $)=($ Pre-exercise body weight - Post-exercise body weight/exercise duration [12] [18] [21]-[26].

A stopwatch was used to record the total exercise time (min).

\subsection{Statistical Analysis}

All results were presented as Means \pm SD. Microsoft Office Excel, 2007 and Graph Pad Prism 5.0 were used to perform statistical analyses. Comparisons between groups were assessed using Analysis of Variance (ANOVA). Relationships between results of different groups were shown via linear regression plots and correlation analyses. The level of statistical significance was set at $\mathrm{P}<0.05$.

\section{Results}

Table 1 showing significant differences $(\mathrm{P}<0.05)$ in the ages, weights, waist circumferences, hip circumferences, waist hip ratios and body surface areas of the four groups studied.

Figure 1 showing the time sweating commenced in the four BMI groups during 15 minutes of moderate exercise. $\mathrm{N}=40$; Means $\pm \mathrm{SD}$. Results show no significant difference $(\mathrm{P}>0.05)$ in time sweating commenced in the groups studied.

Figure 2 showing the sweat rate produced by the women in the different BMI groups. $N=40$; means \pm SD. Obese women had a significantly $(\mathrm{P}<0.05)$ higher sweat rate and underweight women had a significantly $(\mathrm{P}<$ $0.05)$ lower sweat rate than the other groups.

Figure 3 showing Sweat rate $\left(\mathrm{L} \cdot \mathrm{hr}^{-}\right)$expressed per total body-surface area $\left(\mathrm{m}^{2}\right)$. A significant quadratic correlation was observed $(\mathrm{P}<0.05, \mathrm{r}=0.4857)$. $\mathrm{N}=40$; means $\pm \mathrm{SD}$. Subjects with a high body-surface area demonstrated higher sweat rates compared with subjects with low body-surface area.

Figure 4 showing sweat electrolyte $\left(\mathrm{Na}^{+}, \mathrm{K}^{+}\right.$and $\left.\mathrm{Cl}^{-}\right)$concentrations in underweight, normal weight, over- 
Table 1. Anthropometric and baseline data.

\begin{tabular}{ccccc}
\hline Anthropometric data parameters & Underweight & Normal weight & Overweight & Obese \\
\hline Age (years) & $22.50 \pm 2.78^{*}$ & $20.80 \pm 2.10^{*}$ & $21.30 \pm 2.16^{*}$ & $20.60 \pm 2.32^{*}$ \\
Weight (kg) & $46.65 \pm 0.96^{*}$ & $57.09 \pm 1.74^{*}$ & $73.01 \pm 2.56^{*}$ & $94.45 \pm 3.57^{*}$ \\
Height (m) & $1.63 \pm 0.05$ & $1.61 \pm 0.07$ & $1.63 \pm 0.09$ & $1.64 \pm 0.07$ \\
Waist circumference (cm) & $66.19 \pm 3.09^{*}$ & $70.83 \pm 3.59^{*}$ & $82.81 \pm 6.76^{*}$ & $96.10 \pm 7.18^{*}$ \\
Hip circumference (cm) & $86.38 \pm 2.55^{*}$ & $94.29 \pm 7.10^{*}$ & $105.3 \pm 6.00^{*}$ & $118.00 \pm 6.56^{*}$ \\
Waist/hip ratio & $0.77 \pm 0.05^{*}$ & $0.75 \pm 0.04^{*}$ & $0.78 \pm 0.08^{*}$ & $0.82 \pm 0.05^{*}$ \\
Body surface area $\left(\mathbf{m}^{\mathbf{2}}\right)$ & $1.45 \pm 0.06^{*}$ & $1.60 \pm 0.11^{*}$ & $1.82 \pm 0.14^{*}$ & $2.07 \pm 0.16^{*}$ \\
\hline
\end{tabular}

${ }^{*}$ Mean difference statistically significant at $\mathrm{P}<0.05$; SD (standard deviation).

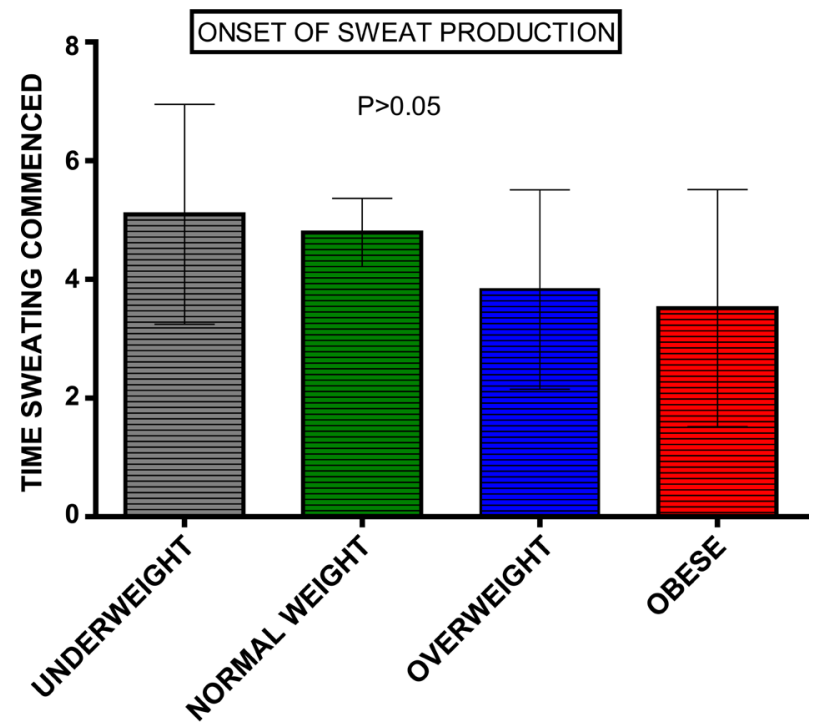

Figure 1. Onset of sweating in the different BMI groups during 15 minutes moderate exercise.

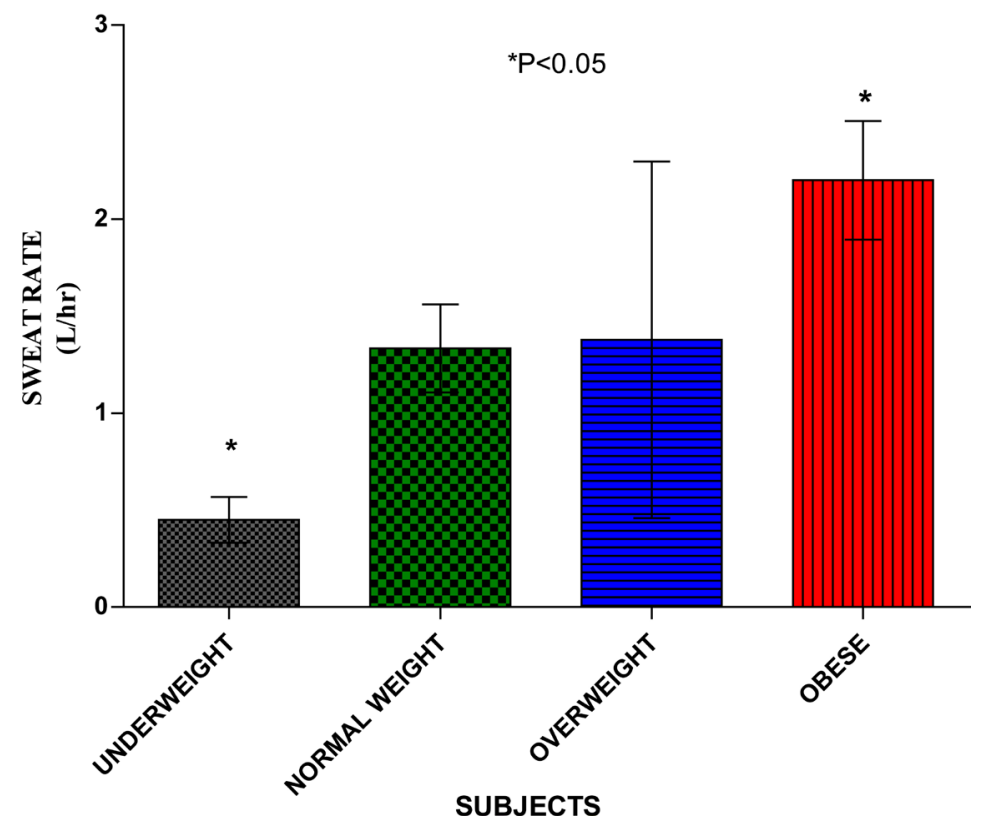

Figure 2. Rate of sweat production in the different BMI groups during 15 minutes of moderate exercise. 


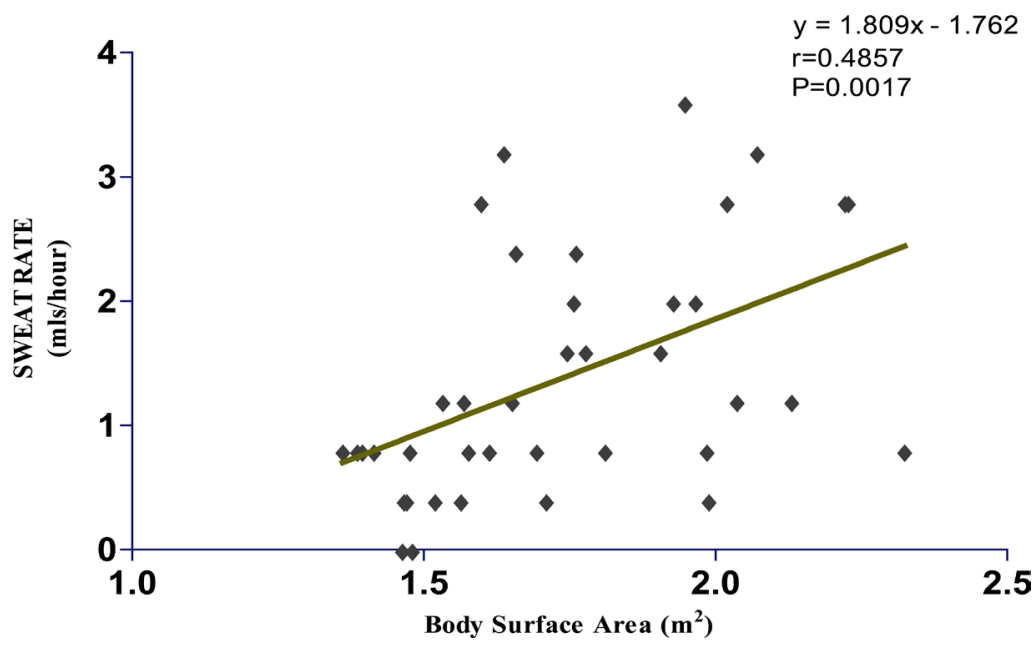

Figure 3. Correlation between body surface area and sweat rate.

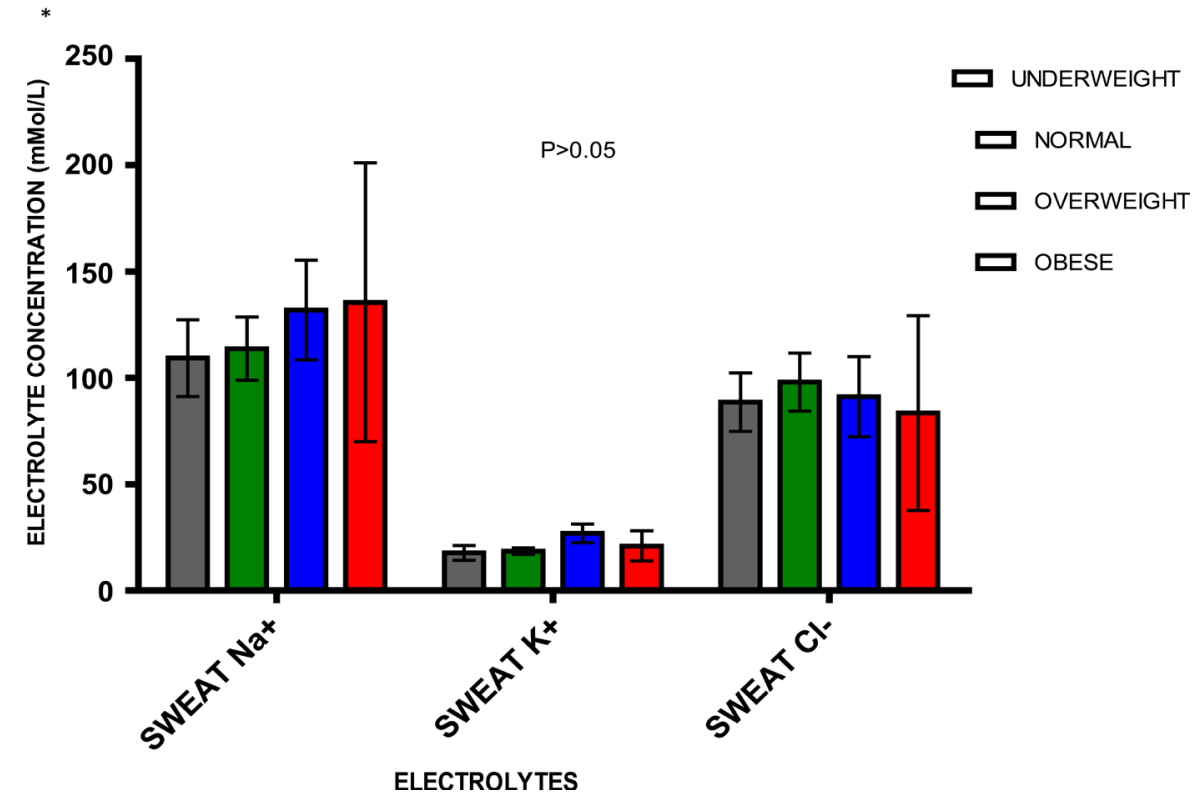

Figure 4. Sweat electrolyte composition in different groups of women during 15 minutes of moderate exercise.

weight and obese ladies during 15 minutes of moderate exercise. $\mathrm{N}=40$; means $\pm \mathrm{SD}$. The results showed that there was no significant change in sweat electrolyte composition in all BMI groups during the exercise.

Figure 5 showing correlation between sweat electrolyte concentration $\left(\mathrm{K}^{+}, \mathrm{Na}^{+}\right.$and $\left.\mathrm{Cl}^{-}\right)$and sweat rate in all four different groups of study. Means $\pm \mathrm{SD} ; \mathrm{N}=40$. The graph indicated a non-significant positive correlation in sweat $\mathrm{Na}^{+}$and $\mathrm{K}^{+}$concentrations $(\mathrm{P}>0.05, \mathrm{r}=0.210$ and $\mathrm{P}>0.05, \mathrm{r}=0.207)$ respectively and a non-significant negative correlation $(\mathrm{P}>0.05, \mathrm{r}=0.032)$ in sweat $\mathrm{Cl}^{-}$concentration.

Figure 6 showing correlation between body mass index and onset of sweating in all four groups of study. $\mathrm{N}=$ 40; Means \pm SD. The graph indicated an inverse relationship (negative correlation) between $(\mathrm{P}>0.05, \mathrm{r}=$ 0.3926) Body Mass Index and time sweating commenced but it was not statistically significant, subjects with a high body mass indices demonstrated lower threshold for sweating when compared with subjects with lower body mass indices.

\section{Discussion}

Obesity is an advantage in cold weather but the same cannot be said of it in hot climates or during exercise. 


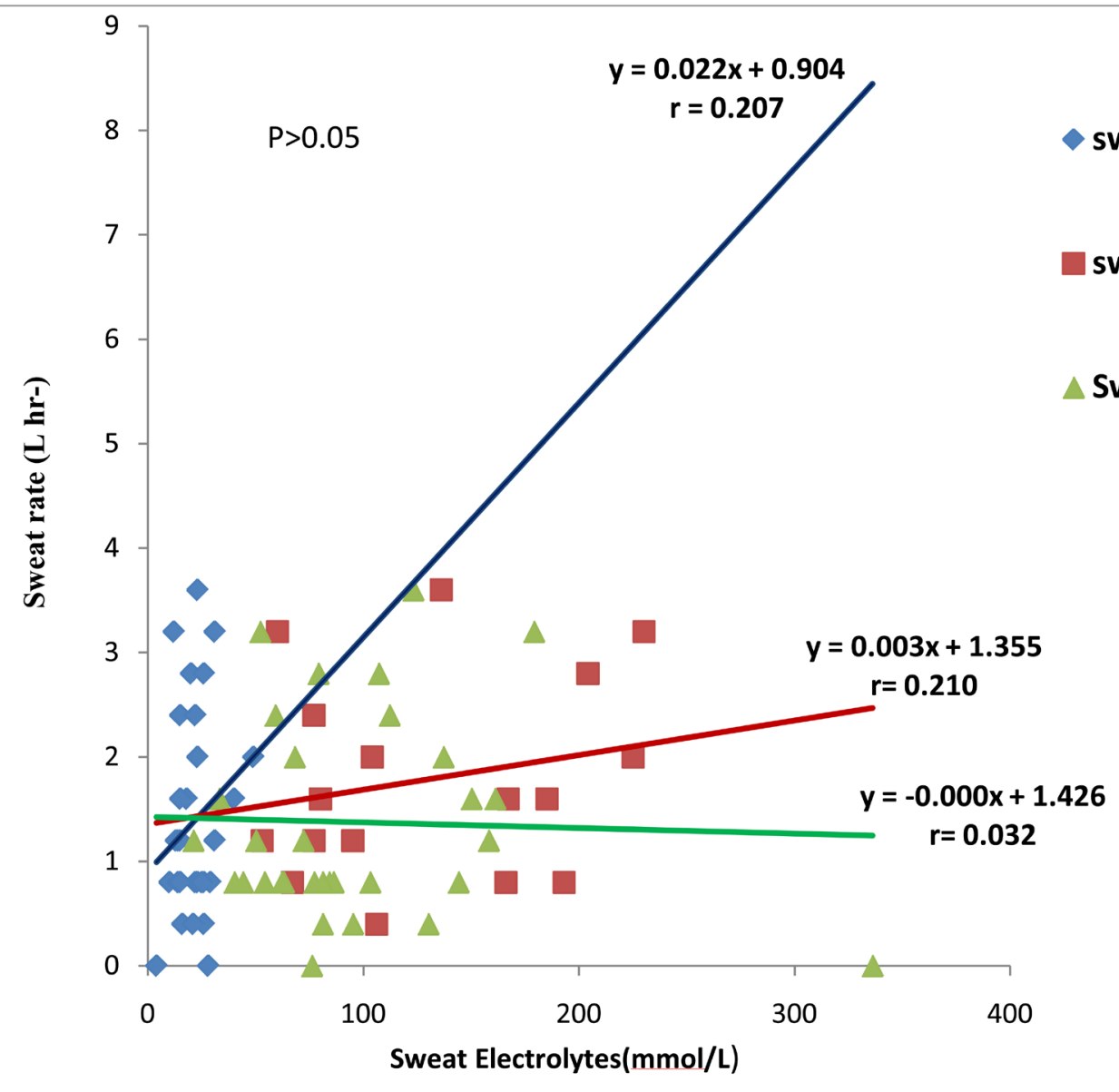

Figure 5. Correlation between sweat electrolyte concentration $\left(\mathrm{K}^{+}, \mathrm{Na}^{+}\right.$and $\left.\mathrm{Cl}^{-}\right)$and sweat rate in women of different BMI groups after 15 mins of moderate exercise.

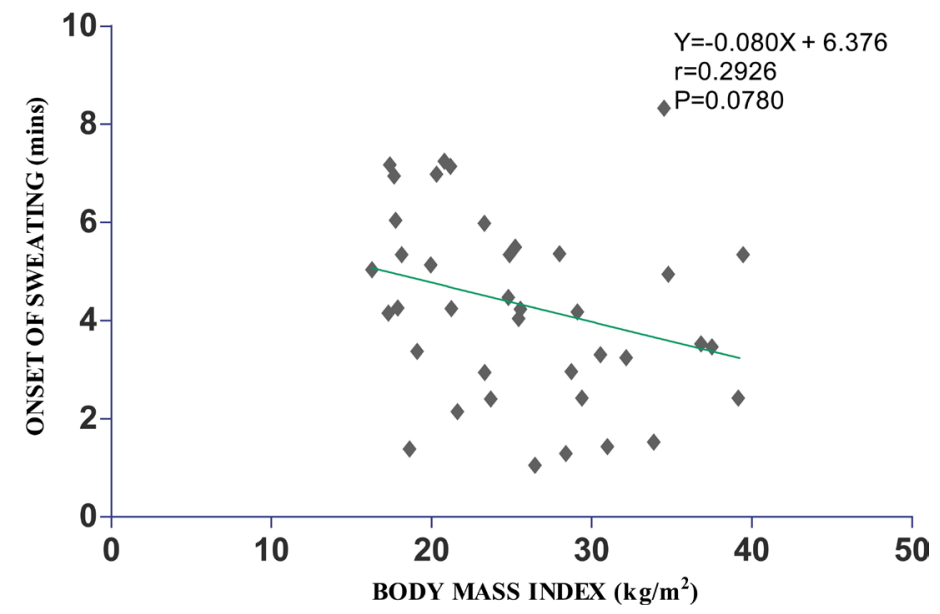

Figure 6. Correlation between BMI and onset of sweating in the different BMI groups after 15 mins of moderate exercise.

High percentage body fat is thought to impede thermoregulation by possibly interfering with heat exchange and increasing metabolic heat production [27]. On the other hand, individuals who are underweight are at a high risk of malnutrition and impaired thermoregulation. Mecklenburg et al. (1974) [28] studied hypothalamic dysfunction in anorexia nervosa patients and found impaired thermoregulatory response which could be as a result of 
hypothalamic dysfunction as a result of starvation. Impaired thermoregulation could also be as a result of decreased fat insulation. Basal Metabolic Rate (BMR) is also thought to be impaired in these individuals.

From this study, we observed that obese subjects produced a significantly higher sweat rate than all the other groups of women while underweight subjects produced significantly lower sweat rates than all the other groups of women. This can probably be accrued to their larger number of sweat glands as well as larger body surface area hence the larger fluid losses [29]. Our work therefore is in agreement with this and the work of Eijsvogels et al. (2011) [15] and in contrast to that of Leites et al. (2013) [13] and Limbaugh et al. (2013) [14] who reported no statistical difference in exercise induced sweating when comparing obese and lean girls and men of similar fitness levels respectively. They therefore concluded that there was no difference in sweat loss between obese and lean and individuals.

Taylor (1986) [30] stated that increases in sweat rate will increase the concentration of $\mathrm{Na}^{+}$in sweat as a result of ductal reduction in $\mathrm{Na}^{+}$reabsorption. Others have suggested that $\mathrm{Na}^{+}$reabsorption has a maximum limit that becomes saturated with increases in sweat rate, therefore causing an increase in $\mathrm{Na}^{+}$concentration in sweat [7] [11] [31]-[33]. It has also been proposed that with increases in sweat rate the sweat $\mathrm{Na}^{+}$reabsorption rate increases proportionally less than the $\mathrm{Na}^{+}$secretion rate, thus resulting in an elevated $\mathrm{Na}^{+}$in sweat [8] [33]. Thus, increase in sweat rate will cause the $\mathrm{Na}^{+}$reabsorptionrate to increase, decrease, or become saturated and thus leading to a plateau effect. Our results showed no significant difference $(\mathrm{P}>0.05)$ in the sweat $\mathrm{Na}^{+}$electrolyte composition in the four BMI groups studied. We observed a non-significant positive correlation between sweat rate and $\mathrm{Na}^{+}$concentration in sweat. A possible reason for our results could be as a result of the shorter duration of exercise and a smaller sample size than other researchers who reported significant positive correlations and $\mathrm{Na}^{+}$electrolyte composition.

There was also a non significant difference in sweat $\mathrm{K}^{+}$composition in the four groups of women studied. Correlation between sweat potassium ion concentration and sweat rate in all four groups of study indicated a non-significant positive correlation. It is established that increase in sweat rate leads to increase in sweat electrolyte loss.

Sweat $\mathrm{Cl}^{-}$concentrations in the four study groups also showed no statistical difference. Correlation between sweat Chloride ion concentration and sweat rate in all four groups of study indicated a non significant negative correlation. This observation was in agreement with the work of Pichan et al. (1988) [34] who reported that the increase in sweat electrolytes is not related to sweat rate and in incongruity with the observations of Ugwu and Oyebola [12].

From this study, we observed an inverse relationship (negative correlation) between Body Mass Index and time sweating commenced but it was not statistically significant, subjects with a high body mass indices demonstrated lower threshold for sweating when compared with subjects with lower body mass indices. This is probably because relative deficit in thermoregulatory ability in the obese and possible reasons for this are the fact that fat has a low specific heat, this implies that a smaller amount of heat is required to increase the temperature of a given mass of fat [35] thus inducing sweating to cool the body. Also, the lower water content of fat compared to most body tissues will infer that any level of hypohydration will denote a relatively higher percentage of water loss in them than lean individuals.

\section{Conclusion}

In conclusion, underweight women demonstrated significantly lower sweat rates while obese women demonstrated significantly higher sweat rates than all the other groups of women. A positive relationship between sweat rate and body surface area was also observed. These observations imply that obese subjects are more likely to develop fluid deficits during moderate exercise and underweight women might be at a thermoregulatory disadvantage during exercise because of their reduced body fat and body surface area.

\section{References}

[1] IUPS Thermal Commission (2001) Glossary of Terms for Thermal Physiology. Japanese Journal of Physiology, 51, 245-280.

[2] Aragon-Vagas, L.F. (2010) Workshop: Sweat Rate Measurement in Athletes. XXXI sFIMS Sports Medicine World Congress Medimond International Proceedings, San Juan, May 2010, 9-14.

[3] Robinson, S. (1942) The Effect of Body Size upon Energy Exchange in Work. American Journal of Physiology, 36, 
363-368.

[4] Amabebe, E., Omorodion, S.I., Ozoene, J.O. and Ugwu, A.C. (2014) Relationship between Menopausal Sweating and Body Mass Index. Open Journal of Endocrine and Metabolic Diseases, 4, 137-146. http://dx.doi.org/10.4236/ojemd.2014.46014

[5] Amabebe, E., Omorodion, S.I., Ozoene, J.O., Ugwu, A.C. and Obika, L.F. (2013) Sweating and Thirst Perception in Premenopausal, Perimenopausal and Postmenopausal Women during Moderate Exercise. Journal of Experimental and Integrative Medicine, 3, 279-284. http://dx.doi.org/10.5455/jeim.280813.or.087

[6] Sato, K. (1977) The Physiology, Pharmacology and Biochemistry of the Eccrine Sweat Gland. Reviews of Physiology, Biochemistry and Pharmacology, 79, 51-31. http://dx.doi.org/10.1007/bfb0037089

[7] Bijman, J. and Quinton, P.M. (1984) Influence of Abnormal Cl Impermeability on Sweating in Cystic Fibrosis. American Journal of Physiology-Cell Physiology, 247, C3-C9.

[8] Inoue, Y., Nakao, M., Ishizashi, H., Tsujita, J. and Araki, T. (1998) Regional Differences in the Na ${ }^{+}$Reabsorption of Sweat Glands. Applied Human Science, 17, 219-221. http://dx.doi.org/10.2114/jpa.17.219

[9] Morgan, R.M., Patterson, M.J. and Nimmo, M.A. (2004) Acute Effects of Dehydration on Sweat Composition in Men during Prolonged Exercise in the Heat. Acta Physiologica Scandinavica, 182, 37-42. http://dx.doi.org/10.1111/j.1365-201x.2004.01305.x

[10] Yoshida, T., Shin-ya, H., Nakai, S., Yorimoto, A., Morimoto, T., Suyama, T. and Sakurai, M. (2006) Genomic and Non-Genomic Effects of Aldosterone on the Individual Variation of the Sweat Sodium Ion Concentration during Exercise in Trained Athletes. European Journal of Applied Physiology, 98, 466-471. http://dx.doi.org/10.1007/s00421-006-0295-5

[11] Buono, M.J., Ball, K. and Kolkhorst, F. (2007) Sodium Ion Concentration vs. Sweat Rate Relationship in Humans. Journal of Applied Physiology, 103, 990-994. http://dx.doi.org/10.1152/japplphysiol.00015.2007

[12] Ugwu, A.C. and Oyebola, D.D.D. (1992) Effects of Temperature and Exercise on Sweat Rate and Sweat Electrolyte Loss in Nigerians. Nigerian Journal of Physiological Sciences, 8, 92-101.

[13] Leites, G.T., Sehl, P.L., Cunha, G.S., Detoni, F.A. and Meyer, F. (2013) Responses of Obese and Lean Girls Exercising under Heat and Thermoneutral Conditions. The Journal of Pediatrics, 162, 1054-1060. http://dx.doi.org/10.1016/j.jpeds.2012.10.047

[14] Limbaugh, J.D., Wimer, G.S., Long, L.H. and Bard, W.H. (2013) Body Fatness, Body Core Temperature and Heat Loss during Moderate-Intensity Exercise. Aviation, Space, and Environmental Medicine, 84, 1153-1158. http://dx.doi.org/10.3357/ASEM.3627.2013

[15] Eijsvogels, T.M.H., Veltmeijer, M.T.W., Schreuder, T.H.A., Poelkens, F., Thijssen, D.H.J. and Hopman, M.T.E. (2011) The Impact of Obesity on Physiological Responses during Prolonged Exercise. International Journal of Obesity, 35, 1404-1412. http://dx.doi.org/10.1038/ijo.2010.277

[16] WHO Expert Consultation (2004) Appropriate Body-Mass Index for Asian Populations and Its Implications for Policy and Intervention Strategies. Lancet, 363, 157-163.

[17] Sawka, M.N., Burke, L.M., Eichner, E.R. and Maughan, R.J. (2007) American College of Sports Medicine Positions Stand. Exercise and Fluid Replacement. Medicine and Science in Sports and Exercise, 39, 377-390.

[18] Ugwu, A.C. and Oyebola, D.D.O. (1996) Sweat Collection Made Simple. Journal of Medical Laboratory Science, 5, 171-176.

[19] Mostellar, R.D. (1987) Simplified Calculation of Body Surface Area. New England Journal of Medicine, 317, 1098. http://dx.doi.org/10.1056/NEJM198710223171717

[20] Bruce, R.A., Blackman, J.R., Jones, J.W. and Straty, G. (1963) Exercise Testing in Adult Normal Subjects and Cardiac Patients. Pediatrics, 32, 742-756.

[21] Ugwu, A.C. (1985) Cardio-Respiratory Changes in Nigerians Sweating under Heat and Exercise Conditions. International Journal of Research Communication Systems, 13, 563-564.

[22] Ugwu, A.C. (1985) Sex Differences in Sweat Rates and Composition in Human Populations Indigenous to a Tropical Hot Humid Climate. International Journal of Research Communication Systems, 13, 938-939.

[23] Ugwu, A.C. (1985) Differences between Sweating Characteristics of Men and Women of Tropical Hot and Humid Climates. International Journal of Research Communication Systems, 13, 1118-1119.

[24] Ugwu, A.C. (1986) The Time Course of Sweat Excretion Among Men of Tropical Hot and Humid Climates. International Journal of Research Communication Systems, 14, 459-460.

[25] Ugwu, A.C. (1987) Calcium and Magnesium Concentrations in Sweat of Normal Nigerian Men Sweating under Heat and Exercise Conditions. Medical Science Research Journal, 15, 1249-1250.

[26] Casa, D.J., Armstrong, L.E., Hillman, S.K., Montain, S.J., Reiff, R.V., Rich, B.S., Roberts, W.O. and Stone, J.A. (2000) 
National Athletic Trainers’ Association Position Statement: Fluid Replacement for Athletes. Journal of Athletic Training, 35, 212-224.

[27] Kolka, M.A. (1992) Temperature Regulation in Women. Medicine, Exercise, Nutrition and Health, 1, 201-207.

[28] Mecklenburg, R.S., Loriaux, D., Lynn, D.L., Thompson, R.H., Andersen, A.E. and Lipsett, M.B. (1974) Hypothalamic Dysfunction in Patients with Anorexia Nervosa. Medicine, 53, 147. http://dx.doi.org/10.1097/00005792-197403000-00003

[29] Havenith, G. and van Middendorp, H. (1990) The Relative Influence of Physical Fitness, Acclimatization State, Anthropometric Measures and Gender on Individual Reactions to Heat Stress. European Journal of Applied Physiology and Occupational Physiology, 61, 419-427.

[30] Taylor, N.A.S. (1986) Eccrine Sweat Glands: Adaptations to Physical Training and Heat Acclimation. Sports Medicine, 3, 387-397. http://dx.doi.org/10.2165/00007256-198603060-00001

[31] Saat, M., Sirisinghe, R.G., Singh, R. and Tochihara, Y. (2005) Effects of Short-Term Exercise in the Heat on Thermoregulation, Blood Parameters, Sweat Secretion and Sweat Composition of Tropic-Dwelling Subjects. Journal of Physiological Anthropology and Applied Human Science, 24, 541-549. http://dx.doi.org/10.2114/jpa.24.541

[32] Shamsuddin, A.K.M., Yanagimoto, S., Kuwahara, T., Zhang, Y., Nomura, C. and Kondo, N. (2005) Changes in the Index of Sweat Ion Concentration with Increasing Sweat during Passive Heat Stress in Humans. European Journal of Applied Physiology, 94, 292-297. http://dx.doi.org/10.1007/s00421-005-1314-7

[33] Nejsum, L.N., Practorius, J. and Nielsen, S. (2005) NKCC1 and NHE1 are Abundantly Expressed in the Basolateral Plasma Membrane of the Secretory Coil Cells in Rat, Mouse and Human Sweat Glands. American Journal of Physiology-Cell Physiology, 289, C333-C340. http://dx.doi.org/10.1152/ajpcell.00228.2004

[34] Pichan, G., Gauttam, R.K., Tomar, O.S. and Bajaj, A.C. (1988) Effect of Primary Hypohydration on Physical Work Capacity. International Journal of Biometeorology, 32, 176-180. http://dx.doi.org/10.1007/BF01045276

[35] Haymes, E.M., McCormick, R.J. and Buskirk, E.R. (1975) Heat Tolerance of Exercising Lean and Obese Prepubertal Boys. Journal of Applied Physiology, 39, 457-461. http://dx.doi.org/10.1249/00005768-197500710-00082 